Научная статья

УДК 338

DOI: $10.17213 / 2075-2067-2021-5-106-112$

\title{
ЭКОНОМИЧЕСКАЯ СОСТАВЛЯЮЩАЯ РАЗРАБОТКИ БИЗНЕС-ПЛАНА ПРЕДПРИЯТИЯ МАШИНОСТРОЕНИЯ: ТЕОРИЯ, МЕТОДОЛОГИЯ, ПРАКТИКА
}

\author{
Виктор Павлович Кузнецов", Наталия Сергеевна Андряшина ${ }^{2}$, \\ Наталья Александровна Бакулина ${ }^{3 凶}$ \\ ${ }^{1,2,3}$ Нижсегородский государственный педагогический университет \\ имени Козьмы Минина, Нижний Новгород, Россия \\ ${ }^{1}$ kuzneczov-vp@mail.ru,ORCID:0000-0002-7849-4720 \\ ${ }^{2}$ natali_andr@bk.ru,ORCID:0000-0002-8209-1764 \\ 3bakulinana@st.mininuniver.ru ${ }^{\bowtie}$
}

\begin{abstract}
Аннотация. Целью статьи является всестороннее исследование совокупности коммуникаций в организации. Для достижения поставленной цели нами была рассмотрена экономическая составляющая бизнес-плана на примере ООО «БЦР МОТОРС».

Методология. В условиях современной рыночной экономики следует четко анализировать и планировать каждую иель и задачу предприятия. Руководству организачии необходимо прорабатывать прочесс планирования, что позволит эффективно проанализировать всю совокупность будущих операций предпринимательской деятельности. С помощью своевременного планирования руководство организации получает возможность для минимизирования внутренних и внешних рисков, которые оказывают непосредственное влияние на деятельность предприятия. Современная экономическая ситуация вынуждает обращать пристальное внимание на планирование внутри фирмы, т.е. составлять бизнесплан. К используемым в статье научным методам относятся сравнительный, причинноследственный и статистический анализ.
\end{abstract}

Результатыл. В статье сделан вывод о том, что от эффективного составления и использования бизнес-плана зависит финансовое состояние и конкурентоспособность предприятия.

Перспективы исследования. Проблема повышения эффективности использования бизнес-планирования занимает иентральное место в работе предприятия.

Ключевые слова: предпринимательская деятельность, бизнес-план, предприятие, финансовое планирование, внутрифирменное управление

Для цитирования: Кузнецов В.П., Андряшина Н.С., Бакулина Н.А. Экономическая составляющая разработки бизнес-плана предприятия машиностроения: теория, методология, практика // Вестник Южно-Российского государственного технического университета. Серия: Социально-экономические науки. 2021. T. 14, №5. C. 106-112. http:// dx.doi.org/10.17213/2075-2067-2021-5-106-112.

(C) Кузнецов В.П., Андряшина Н.С., Бакулина Н.А., 2021 
Original article

\title{
THE ECONOMIC COMPONENT \\ OF THE DEVELOPMENT OF A BUSINESS PLAN \\ OF A MACHINE-BUILDING ENTERPRISE: THEORY, METHODOLOGY, PRACTICE
}

\author{
Viktor P. Kuznetsov ${ }^{1}$, Natalia S. Andryashina ${ }^{2}$, Natalia A. Bakulina ${ }^{3 凶}$ \\ 1, 2, ${ }^{3}$ Minin Nizhny Novgorod State Pedagogical University, Nizhny Novgorod, Russia \\ ${ }^{1}$ kuzneczov-vp@mail.ru, ORCID:0000-0002-7849-4720 \\ 2natali_andr@bk.ru,ORCID:0000-0002-8209-1764 \\ ${ }^{3}$ bakulinana@st.mininuniver.ru ${ }^{\boxplus}$
}

\begin{abstract}
The purpose of the article is a comprehensive study of the totality of communications in an organization. To achieve this goal, we considered the economic component of the business plan using the example of BCR MOTORS LLC.

Methodology. In a modern market economy, it is necessary to clearly analyze and plan each goal and objective of the enterprise. The management of the organization needs to work out the planning process, which will effectively analyze the entire set of future business operations. With the help of timely planning, the organization's management gets the opportunity to minimize internal and external risks that have a direct impact on the activities of the enterprise. The current economic situation forces us to pay close attention to planning within the company, i.e. draw up a business plan. The scientific methods used in the article include comparative, causal and statistical analysis.

Results. The article concludes that the financial condition and competitiveness of an enterprise depends on the effective preparation and use of a business plan.

Research prospects. The problem of increasing the efficiency of the use of business planning is central to the work of the enterprise.

Keywords: entrepreneurial activity, business plan, enterprise, financial planning, in-house management

For citation: Kuznetsov V.P., Andryashina N.S., Bakulina N.A. The economic component of the development of a business plan of a machine-building enterprise: theory, methodology, practice /I Bulletin of the South Russian State Technical University. Series: Socio-economic Sciences. 2021; 14(5): 106-112. (In Russ.). http://dx.doi.org/10.17213/2075-2067-2021-5-106-112.
\end{abstract}

Введение. Успешной реализации любого предпринимательского проекта обязательно предшествует экономическое обоснование эффективности данной задумки, т.е. проработка и составление бизнес-плана. Бизнес-план - это определенный документ, в котором подробно и четко описываются основополагающие цели задачи конкретного проекта, условия достижения максимальных результатов. Данный документ должен подтверждать правильность и эффективность намеченного пути развития предприятия.

Любой бизнес-план рассчитан на будущую перспективу и чаще всего рассматривается на следующие три года. Однако при создании бизнес-плана предприятия на следующие три года руководители предприятий российского рынка сталкиваются с проблемой непостоянности и высокой динамичности современного рынка. Стоит учитывать, что в условиях современного рынка эконо- 
мическая ситуация нестабильна и постоянно изменяется, что является определенной проблемой при планировании деятельности в будущем. Считается, что планирование деятельности, т.е. составление бизнес-плана российского предприятия на период, превышающий год, является заведомо ошибочным, т.е. бесполезным, и основная масса инвесторов не рассматривает бизнес-планы, рассчитанные на перспективу более одного календарного года [4].

В современных условиях, когда экономика страны носит стихийный характер, т.е. имеет место принцип неожиданности, финансовое планирование необходимо для защиты предприятия от влияния негативных внешних факторов, для обеспечения финансовой устойчивости, достижения высокого результата финансово-хозяйственной деятельности. В рыночной экономике, где развита конкуренция, где налоговое законодательство сурово в своих нормах, планирование позволяет защитить предприятие и обезопасить от неожиданного ухудшения финансового состояния и, возможно, даже банкротства.

Объектом нашего исследования является бизнес план ООО «БЦР МОТОРС» города Нижний Новгород, которое занимается реализацией автомобилей и автозапчастей к ним.

Целью статьи является всестороннее исследование совокупности коммуникаций в организации. Для достижения поставленной цели нами была рассмотрена экономическая составляющая бизнес-плана на примере ООО «БЦР МОТОРС».

Компания «БЦР МОТОРС» является официальным дилером КІА (КИА) в Нижнем Новгороде с 2009 года. Организационно-правовая форма предприятия - общество с ограниченной ответственностью.

Методика. План, который был разработан техническим отделом, должен обеспечить создание нового прогрессивного имиджа и стиля предприятия. Такая разработка позволяет предприятию автомобильного бизнеса представать в глазах потребителей в более выгодном свете.

Проведение переоборудования и реконструкции дилерского центра вызвало определенные трудности и крупные финансовые затраты (по требованиям официального дистрибьютора дилерский центр должен быть оснащён только оригинальным дорогостоящим оборудованием). Все доходы, которые предприятие получает в данный период времени, направлены на покрытие расходов, связанных с реконструкцией дилерского центра и стоянки.

Для обеспечения преимущества перед конкурентами и эффективной работы предприятия необходимо закупить крупную партию товаров у дистрибьютора. Данная партия товара имеет более усовершенствованные качественные и эстетические характеристики, что в свою очередь обеспечит выход организации на новый уровень на автомобильном рынке.

Результаты. Все проведенные мероприятия и реализация новой партии товаров позволит получить значительный эффект в течение 3 лет. Ориентировочный темп прироста чистой прибыли планируется 15-20\% по отношению к текущей [2].

Нами было рассмотрена специализация, качество услуг, уровень цен каждого потенциального конкурента. По итогам данного исследования было выявлено, что основными конкурентами компании являются такие автосервисные предприятия, как «Audi-центр» и гаражные сервисы и кооперативы. Основными конкурентными свойствами автомобилей КІА являются массовая доступность, привлекательный дизайн, просторный и комфортный вместительный салон, надежный и мощный двигатель, низкий расход топлива, надежная подвеска, хорошая проходимость, хорошая управляемость, хорошие тормоза, высокое качество сборки и недорогие запчасти.

Обсуждение. Для того чтобы лучше разобраться в структуре парка импортных автомобилей, необходимо рассмотреть таблицу 1.

Из таблицы 1 видно, что наиболее распространёнными марками иностранных производителей в городе Нижний Новгород являются автомобили Nissan, Volkswagen, Reno, Volvo, Audi, Opel, Skoda, Kia и др. Наглядно структура представлена на рисунке 1.

В Нижнем Новгороде система автосервисных услуг начала набирать мощный про- 


\section{Структурный состав парка импортных легковых автомобилей}

\section{в городе Нижний Новгород \\ Structural composition of the fleet of imported passenger cars in Nizhny Novgorod}

\begin{tabular}{|l|c|}
\hline \multicolumn{1}{|c|}{ Наименование марок автомобиля } & Количество a/м, ед. \\
\hline Nissan & 3000 \\
\hline Volkswagen & 1900 \\
\hline Reno & 1350 \\
\hline Volvo & 1000 \\
\hline Audi & 1300 \\
\hline Opel & 950 \\
\hline Skoda & 1800 \\
\hline Kia & 2400 \\
\hline Остальные марки автомобилей & 7000 \\
\hline Итого: & 20700 \\
\hline
\end{tabular}

изводственный потенциал. Это объясняется тем, что парк автомобилей импортного производства растёт высокими темпами. Соответственно и уровень конкуренции между авто дилерами возрастает.

По результатам анализа финансовой части бизнес-плана предприятия нами было выявлено, что наибольший удельный вес в структуре имущества ООО «БЦР МОТОРС» в 2018 году составляли оборотные активы $(99,43 \%)$. К 2020 году ситуация не изменилась, и наибольшую долю имущества также составили оборотные активы $(99,32 \%)$. В составе оборотных активов наибольший вес занимают запасы, их доля увеличилась приблизительно с $33,09 \%$ до $41,8 \%$. По всем статьям произошло снижение, что означает перевод капитала во внеоборотные активы. Снизилась доля денежных средств с 0,98\% в 2018 году до $0,51 \%$ в 2020 году, что с одной стороны свидетельствует об ухудшении ликвидности, a с другой - о достаточно эффективном использовании денежных средств. Доля дебиторской задолженности снизилась с 64,1\% до 9,8\%, что говорит об интенсивных расчётах с предприятиями дебиторов [3].

В структуре внеоборотных активов наибольший удельный вес занимают основные средства, их доля увеличилась приблизительно с $0,57 \%$ до $0,67 \%$ за анализируемый период.

Произошло повышение удельного веса собственных средств на $8,5 \%$ в основном за счёт увеличения нераспределённой прибыли, т.к. уставный капитал на протяжении изучаемого периода остался неизменным, а добавочный и резервный капиталы отсутствуют.
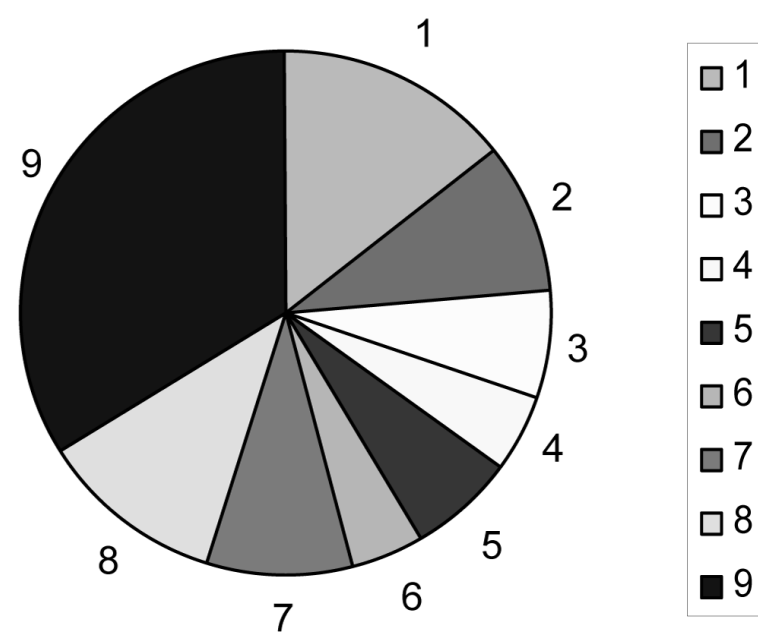

Рис. 1. Структура парка импортных автомобилей

Fig. 1. Structure of the fleet of imported cars 
Заключение. По итогам нашего исследования был сделан вывод о том, что проведение переоборудования и реконструкции дилерского центра вызвало определенные трудности и крупные финансовые затраты (по требованиям официального дистрибьютора дилерский центр должен быть оснащён только оригинальным дорогостоящим оборудованием). Все доходы, которые предприятие получает в данный период времени, направлены на покрытие расходов, связанных с реконструкцией дилерского центра и стоянки.

Для обеспечения преимущества перед конкурентами и эффективной работы предприятия необходимо закупить крупную партию товаров у дистрибьютора.

Все проведенные мероприятия и реализация новой партии товаров позволит получить значительный эффект в течение 3 лет. Ориентировочный темп прироста чистой прибыли планируется 15-20\% по отношению к текущей [1].

Руководству ООО «БЦР МОТОРС» необходимо проводить повышение квалификации работников, стимулировать их самостоятельно совершенствовать свой образовательный и квалификационный уровень. Более квалифицированные работники будут выполнять поручения не только быстрее, но и качественнее. Это позволит улучшить результаты деятельности данного предприятия и его финансовое состояние.

\section{Список источников}

1. Андряшина Н.С., Романовская Е.В., Ражова Н.А., Сергеева Д.С. Развитие производственного потенциала промышленного предприятия // Экономика и предпринимательство. Нижний Новгород: Изд-во Нижегородского гос. пед. университета, 2018. №8(97). С. 917-922.

2. Бакулина Н.А., Шабаров А.А., Кузнецов В.П. Сущность организации производства // В сборнике: Промышленное развитие России: проблемы, перспективы. Сборник статей по материалам XVIII Международной научно-практической конференции преподавателей вузов, ученых, специалистов, аспирантов, студентов: в 2-х томах. Нижний Новгород: Изд-во Ниже- городского гос. пед. университета, 2021. C. $12-15$.

3. Горбунов В.Л. Бизнес-планирование с оценкой рисков и эффективности проектов: научно-практическое пособие. М.: ИЦ РИОР, НИЦ ИНФРА-М, 2017. 248 с.

4. Немети Л. Стратегии выхода из бизнеса: планирование выхода, опционы, увеличение стоимости бизнеса, управление сделками для владельцев бизнеса. М.: Инфотропик Медиа, 2018. 272 с.

5. Пасечник А.С., Кузнецов В. П. Анализ проблемы стимулирования труда и мотивации на предприятиях малого предпринимательства // В сборнике: Экономическое развитие России: тенденции, перспективы. Сборник статей по материалам VI Международной студенческой научно-практической конференции преподавателей, ученых, специалистов, аспирантов, студентов: в 2-х томах. Нижний Новгород: Изд-во Нижегородского гос. пед. университета, 2020. C. 39-42.

6. Руткаускас Т.К., Журухин Г.И. Экономика предприятия: учебник / Екатеринбург: Изд-во Рос. гос. проф.-пед. университета, 2014. 9 c.

7. Kuznetsova S.N., Kuznetsov V.P., Garina E.P., Romanovskaya E. V., Garin A.P. Business model of contract productions // Lecture Notes in Networks and Systems. Zug: Springer Nature Switzerland, 2020. Vol. 111. Pp. 21-29.

8. Potashnik Y.S., Kuznetsov V.P., Garina E.P., Romanovskaya E.V., Andryashina N.S. About the place and role of risk management in the adoption of management decisions at the enterprise // Lecture Notes in Networks and Systems. Zug: Springer Nature Switzerland, 2020. Vol. 111. Pp. 3-9.

9. Kuznetsova S. N., Garina E.P., Kuznetsov V.P., Romanovskaya E. V., Andryashina N.S. Industrial parks formation as a tool for development of long-range manufacturing sectors / Journal of Applied Economic Sciences. Zug: Springer Nature Switzerland, 2017. Vol. 12. №2 (48). Pp. 391-401.

10. Romanovskaya E. V., Garina E.P., Andryashina N. S., Kuznetsov V.P., Garin A.P. Product creation system in the conditions of high-tech transformation of the economic system // Lecture Notes in Networks and Systems. Zug: Springer Nature Switzerland, 2020. Vol. 129LNNS. Pp. 289-295. 


\section{References}

1. Andrjashina N.S., Romanovskaja E.V., Razhova N.A., Sergeeva D.S. Razvitie proizvodstvennogo potenciala promyshlennogo predprijatija [Development of the production potential of an industrial enterprise]. Jekonomika $i$ pred-prinimatel'stvo [Economics and entrepreneurship]. Nizhny Novgorod: Izd-vo Nizhegorodskogo gos. ped. universiteta, 2018; 8 (97): 917-922. (In Russ.).

2. Bakulina N.A., Shabarov A.A., Kuznecov V.P. Sushhnost' organizacii proizvodstva [The essence of the organization of production]. V sbornike: Promyshlennoe razvitie Rossii: problemy, perspektivy. Sbornik statej po materialam XVIII Mezhdunarodnoj nauchno-prakticheskoj kon-ferencii prepodavatelej vuzov, uchenyh, specialistov, aspirantov, studentov: v 2-h tomah [In the collection: Industrial development of Russia: problems, prospects. Collection of articles based on the materials of the XVIII International Scientific and Practical Conference of university teachers, scientists, specialists, postgraduates, students: in 2 volumes]. Nizhny Novgorod: Izd-vo Nizhegorodskogo gos. ped. universiteta, 2021. Pp. 12-15. (In Russ.).

3. Gorbunov V.L. Biznes-planirovanie $s$ ocenkoj riskov i jeffektivnosti pro-ektov: Nauchno-prakticheskoe posobie [Business planning with risk assessment and project effectiveness: a scientific and practical guide]. Moscow: IC RIOR, NIC IN-FRA-M, 2017. 248 p. (In Russ.).

4. Nemeti L. Strategii vyhoda iz biznesa: planirovanie vyhoda, opciony, uvelichenie stoimosti biznesa, upravlenie sdelkami dlja vladel'cev biznesa [Exit strategies from business: exit planning, options, business value increase, transaction management for business owners]. Moscow: Infotropik Media, 2018. 272 p. (In Russ.).

5. Pasechnik A. S., Kuznecov V.P. Analiz problemy stimulirovanija truda i motivacii na predprijatijah malogo predprinimatel'stva [Analysis of the problem of labor stimulation and motivation at small business enterprises]. V sbornike: Jekonomi-cheskoe razvitie Rossii: tendencii, perspektivy. Sbornik statej po materialam VI Mezhdunarodnoj studencheskoj nauchno-prakticheskoj konferencii prepodavatelej, uchenyh, specialistov, aspirantov, studentov: $\mathrm{v}$ 2-h tomah [In the collection: Economic development of Russia: trends, prospects. Collection of articles based on the materials of the VI International Student Scientific and Practical Conference of teachers, scientists, specialists, graduate students, students: in 2 volumes]. Nizhny Novgorod: Izd-vo Nizhegorodskogo gos. ped. universiteta, 2020. Pp. 39-42. (In Russ.).

6. Rutkauskas T.K., Zhuruhin G.I. Jekonomika predprijatija: uchebnik [Enterprise economics: textbook] / Ekaterinburg: Izd-vo Ros. gos. prof.-ped. universiteta, 2014. 9 p. (In Russ.).

7. Kuznetsova S.N., Kuznetsov V.P., Garina E. P., Romanovskaya E. V., Garin A.P. Business model of contract productions // Lecture Notes in Networks and Systems. Zug: Springer Nature Switzerland, 2020. Vol. 111. Pp. 21-29.

8. Potashnik Y.S., Kuznetsov V.P., Garina E.P., Romanovskaya E. V., Andryashina N.S. About the place and role of risk management in the adoption of management decisions at the enterprise // Lecture Notes in Networks and Systems. Zug: Springer Nature Switzerland, 2020. Vol. 111. Pp. 3-9.

9. Kuznetsova S. N., Garina E.P., Kuznetsov V.P., Romanovskaya E. V., Andryashina N. S. Industrial parks formation as a tool for development of long-range manufacturing sectors / Journal of Applied Economic Sciences. Zug: Springer Nature Switzerland, 2017. Vol. 12. №2 (48). Pp. 391-401.

10. Romanovskaya E. V., Garina E. P., Andryashina N. S., Kuznetsov V.P., Garin A.P. Product creation system in the conditions of high-tech transformation of the economic system// Lecture Notes in Networks and Systems. Zug: Springer Nature Switzerland, 2020. Vol. 129 LNNS. Pp. 289-295.

Статья поступила в редакцию 02.09.2021; одобрена после рецензирования 20.09.2021; принята к публикации 22.09.2021.

The article was submitted on 02.09.2021; approved after reviewing on 20.09.2021; accepted for publication on 22.09.2021. 


\section{ИНФОРМАЦИЯ ОБ АВТОРАХ}

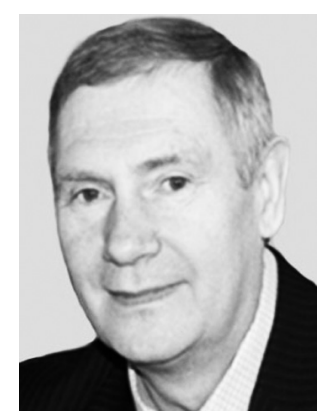

Кузнецов Виктор Павлович - доктор экономических наук, профессор кафедры «Экономика предприятий», Нижегородский государственный педагогический университет имени Козьмы Минина.

Россия, г. Нижний Новгород, ул. Челюскинцев, 9

Viktor P. Kuznetsov - Doctor of Economic Sciences, Professor of the Department of Enterprise Economics, Minin Nizhny Novgorod State Pedagogical University.

9 Chelyuskintsev st., Russia, Nizhny Novgorod

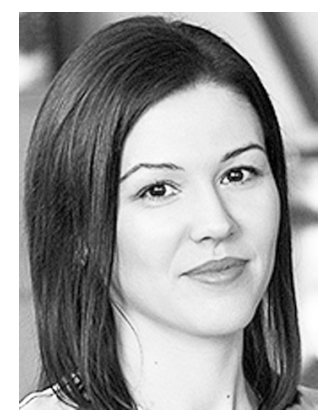

Андряшина Наталия Сергеевна - кандидат экономических наук, доцент кафедры «Экономика предприятий», Нижегородский государственный педагогический университет имени Козьмы Минина.

Россия, г. Нижний Новгород, ул. Челюскинцев, 9

Nataliya S. Andryashina - Candidate of Economic Sciences, Associate Professor of the Department of Enterprise Economics, Minin Nizhny Novgorod State Pedagogical University.

9 Chelyuskintsev st., Russia, Nizhny Novgorod

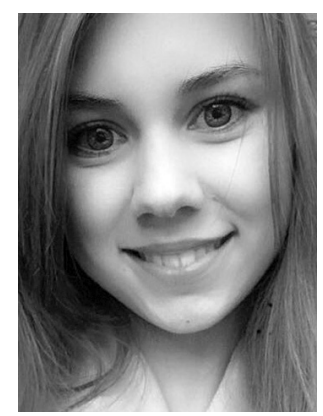

Бакулина Наталья Александровна - магистрант кафедры «Профессиональное образование и управление образовательными системами», Нижегородский государственный педагогический университет имени Козьмы Минина.

Россия, г. Нижний Новгород, ул. Челюскинцев, 9

Natalya A. Bakulina - Undergraduate Student of the Department of Professional Education and Management of Educational Systems, Minin Nizhny Novgorod State Pedagogical University.

9 Chelyuskintsev st., Russia, Nizhny Novgorod

Вклад авторов:

Кузнецов В. П. - научное руководство; концепция исследования; развитие методологии; написание исходного текста; итоговые выводы.

Андряшина Н. С. - доработка текста; итоговые выводы.

Бакулина Н. А. - доработка текста; итоговые выводы.

\section{Contribution of the authors:}

Kuznetsov V.P. - scientific leadership; research concept; development of methodology; writing the source text; final conclusions.

Andryashina N.S. - revision of the text; final conclusions.

Bakulina N.A. - revision of the text; final conclusions. 